\title{
PATENTES E REGULAÇÃO ECONÔMICA APLICADA AOS FÁRMACOS
}

\author{
Daniel Amin Ferraz \\ Centro Universitário de Brasília - UniCEUB, Brasília \\ Rafael Arcuri \\ Centro Universitário de Brasília - UniCEUB, Brasília
}

\begin{abstract}
RESUMO: O presente trabalho tem como objetivo demonstrar que a Teoria do Interesse Público não é capaz de explicar porque existem patentes de fármacos, mas a Teoria da Escolha Pública sim. Para que a Teoria do Interesse Público pudesse explicar o sistema de patentes, tal sistema teria que ser a regulação que mais elevasse o bem-estar da população. Porém, os estudos e as justificativas formais que defendem o modelo patentário ignoram a competição entre patentes que tenham o mesmo fim terapêutico. Se a escolha política entre as formas de regulação simplesmente ignora os fatos relevantes para aferir o bem-estar social - a troca entre exclusão e acesso - ela não pode se justificar como sendo a regulação que melhor representa o interesse público. A metodologia da pesquisa é hipotético-dedutiva, uma vez que foram utilizados testes com o objetivo de corroborar a hipótese de que a Teoria do Interesse Público seria capaz de explicar porque existem patentes de fármacos. Como esses testes falharam, testou-se a hipótese de que a Teoria da Escolha Pública seria capaz de explicar porque existem patentes de fármacos. A conclusão é que esta última se manteve sólida, não sendo falseada. A pesquisa se justifica uma vez que não existem outros trabalhos semelhantes e seu valor decorre da utilidade das suas conclusões para o debate das políticas públicas relacionadas a patentes de fármacos.
\end{abstract}

PALAVRAS-CHAVE: Patentes. Fármacos. Competição intra patentes. Competição entre patentes.

\section{Patents and economic regulation applied to pharmaceuticals}

\begin{abstract}
This paper aims to show that the Public Interest Theory is not able to explain why there are patents for drugs, but the Public Choice Theory does. In order for the Public Interest Theory to explain the patent system, such a system would have to be the regulation that most increased the welfare of the population. However, the studies and formal justifications that support the patent system ignore the competition between patents that have the same therapeutic purpose. If the political choice between forms of regulation simply ignores the relevant facts for measuring social welfare - the exchange between exclusion and access - it can not be justified as the regulation that best represents the public interest. The research methodology is hypotheticaldeductive since tests were used to corroborate the hypothesis that the Public Interest Theory would be able to explain why there are patents for drugs. As these tests failed, the Public Choice Theory hypothesis was tested to see if it would be able to explain why there are pharmaceutical patents. The conclusion is that the latter has remained solid and not been falsified. The research is justified since there are no other similar works and its value derives from the usefulness of its conclusions for the debate of public policies related to drug patents.
\end{abstract}

KEYWORDS: Patents. Pharmaceuticals. Within-Patent Competition. Between-Patent Competition. 


\section{INTRODUÇÃO}

$\mathrm{O}$ acesso à tecnologia, incorporada ao capital, aos bens ou ao conhecimento, é condição do exercício das distintas atividades econômicas e constitui elemento determinante na capacidade competitiva das empresas ${ }^{1}$.

Os contratos de transferência de tecnologia constituem a forma normal de acesso a esse fator de produção (a tecnologia de desenvolvimento). Assim, os investimentos em longo prazo em investigação e tecnologia constituem um dos mecanismos fundamentais para que uma economia industrializada mantenha sua taxa de conhecimento e sua quota de inserção no comércio internacional.

Tal situação é agravada pela prática comum de transferência da tecnologia pelos pacotes tecnológicos, sendo difícil para o adquirente o conhecimento de todos os elementos que fazem parte da tecnologia adquirida. Tal condição gera a eterna dependência econômica e tecnológica do adquirente com relação ao cedente. Todas essas restrições, quando praticadas em larga escala, são suscetíveis, até mesmo, de afetar a independência econômica dos Estados.

Por constatar as características acima elencadas, especialmente a partir do final dos anos 60 do século passado, em um número considerável de países em desenvolvimento adotou-se legislação específica no domínio da transferência de tecnologia.

De maneira geral, tais legislações (que têm base na carta de Direitos e Deveres Econômicos dos Estados aprovados pela Assembleia Geral das Nações Unidas) conferem poderes de intervenção aos Estados.

A intervenção poderia estar caracterizada de forma múltipla: a) necessidade de autorização estatal para a celebração de contratos de transferência de tecnologia entre empresas nacionais e estrangeiras; b) imposição de determinadas cláusulas previstas em lei no âmbito dos contratos; c) proibição de condições restritivas para o adquirente da tecnologia; d) imposição de cláusulas favoráveis a empresa nacional ou ao país acolhedor da tecnologia (principalmente em matéria de formação de recursos humanos, utilização de recursos locais, preservação do meio ambiente, etc. $)^{2}$.

Não obstante, sabe-se hoje que a simples intervenção do Estado como meio de limitar a realização da transferência de tecnologia não é a estratégia mais benéfica, já que gera atraso no desenvolvimento tecnológico e social para os países periféricos.

A transferência de tecnologia deriva de distintas necessidades para o desenvolvimento das atividades humanas (organização da sociedade civil) e empresariais. Assim, pode se dar em virtude do investimento estrangeiro, envolvendo a construção ou instalação de estabelecimentos e equipamentos industriais (tecnologia incorporada ao capital); venda de bens de capital ou bens intermediários (tecnologia incorporada ao capital); trabalho humano qualificado, incluindo a assistência técnica e a formação técnica (tecnologia incorporada ao conhecimento); informação,

1 Hoje em dia, para além da competitividade das empresas, há que se falar na competitividade entre países. E já não mais se leva em consideração, tão somente, elementos como preço relativo e custos. Leva-se em consideração fatores mais amplos e heterogêneos, tais como qualidade das instituições governamentais, marco regulatório, eficácia dos mercados de produtos e serviços, capital humano e social, e, em especial, a inovação (MAS VERDÚ 2010).

2 No sentido da dependência econômica dos países da periferia capitalista com relação aos países de economia central, ver: FERRAZ, Daniel Amin. A concentração empresarial no contexto da economia internacional. In: FERRAZ, Daniel Amin (Org.). Direito empresarial: marco jurídico de internacionalização das empresas brasileiras. Curitiba: CRV, 2012. p. $10-31$. 
de natureza técnica e comercial, protegida pelos direitos da propriedade industrial, exemplo maior a patente, etc (SANTOS, 1984).

No Brasil, as garantias aos bens imateriais possuem, inclusive, proteção constitucional, como consta no artigo $5^{\circ}$, inciso XXIX, da Constituição Federal (BRASIL, 1988):

\begin{abstract}
XXIX - a lei assegurará aos autores de inventos industriais privilégio temporário para sua utilização, bem como proteção às criações industriais, à propriedade das marcas, aos nomes de empresas e a outros signos distintivos, tendo em vista o interesse social e o desenvolvimento tecnológico e econômico do País.
\end{abstract}

Dessa forma, o presente artigo tem como objetivo mostrar a incoerência que existe em justificar o sistema de patentes - especificamente as patentes de fármacos - como sendo o representante do interesse público, já que não existem estudos comparando seus resultados regulatórios com as outras formas de regulação que, teoricamente, também seriam capazes de alcançar o mesmo objetivo ${ }^{3}$.

Existindo mais de uma maneira de se alcançar determinado fim - resolver a falha de mercado que gera subinvestimento em P\&D, que aumenta as chances de inovação bem-sucedida -, só se saberá qual delas melhor representa o interesse público se, no mínimo, forem comparadas entre si e a que obtiver o melhor resultado for a escolhida.

A primeira parte do texto abordará alguns conceitos sobre patentes e o que se entende por Teoria do Interesse Público e Teoria da Escolha Pública. A segunda parte delimitará o problema a ser resolvido pela regulação - concessão, pelo Estado, de direitos exclusivos de exploração de inovações por meio das patentes - e introduzirá uma metodologia de comparação entre possíveis formas de regulação para que o ente político alcance o melhor resultado. Por seu turno, a terceira parte enunciará as falhas nas justificativas tradicionais do sistema de patentes, que ignoram a competição entre patentes diferentes ao avaliar os resultados da regulação. Do todo, ter-se-ia como hipótese o entendimento de que as patentes de fármacos não poderiam ser justificadas pela Teoria do Interesse Público, mas poderiam ser explicadas pela Teoria da Escolha Pública.

A metodologia da pesquisa aplicada no presente artigo é a hipotético-dedutiva, uma vez que foram utilizados testes com o objetivo de corroborar a hipótese de que a Teoria do Interesse Público seria capaz de explicar porque existem patentes de fármacos. Como esses testes falharam, testou-se a hipótese de que a Teoria da Escolha Pública seria capaz de explicar porque existem patentes de fármacos. A conclusão é que esta última se manteve sólida, não sendo falseada.

3 Importa referir que os sistemas poderiam se enquadrar em categorias, dependendo de suas condições de comportamento, nos seguintes termos: i) constantemente estáveis, qualificados como aqueles estritamente rígidos, estando completos quando o resultado ou objetivo é cumprido; ii) periodicamente estáveis, se constituídos por ciclos que se repetem habitualmente; e, finalmente, iii) caóticos, quando a linearidade dos sistemas anteriores é substituída pela imprevisibilidade. O sistema jurídico, por mais que possa se pretender linear está mais assemelhado a um conjunto caótico, como mínimo complexo (PORTUGAL, 2017). 


\section{ESCOLHAS POLÍTICAS}

\subsection{Definição, efeitos esperados e justificativa para a existência de uma patente}

A patente é uma tentativa jurídica de tornar escasso um bem naturalmente não escasso (PLANT, 1934). Essa escolha política, porém, não é auto evidente ${ }^{4}$. Caso não exista a escassez de um bem - caso ele seja abundante para além dos usos possíveis -, não há necessidade de que ele seja partilhado (HUME, 2013).

Por quê deve-se repartir bens que, caso não repartidos, não causarão transtornos (HUME, 2013)? Exatamente por serem abundantes, esses bens não gerarão conflitos entre pessoas com interesses diferentes. As regras de propriedade se fazem necessárias quando a natureza não proporciona todos os bens de forma abundante e, a partir do momento que eles são escassos, seus usos são - ou podem ser - conflitantes (HUME, 2013).

As patentes, por outro lado, diferentemente da propriedade privada comum, não são a consequência da escassez dos bens (PLANT, 1934). Enquanto a propriedade "tradicional" (bens materiais) lida com a escassez dos bens, a propriedade intelectual cria a escassez de bens naturalmente não-escassos.

Se a propriedade intelectual - como é o caso das patentes - cria o problema que a propriedade tradicional tenta resolver, deve haver uma justificativa para tanto. $\mathrm{O}$ efeito esperado de uma patente é que ela aumente o preço de um bem não-escasso. Havendo demanda para um determinado bem, seu preço será diretamente influenciado por sua oferta - sua escassez. O preço será uma função entre oferta e demanda. Caso o bem seja ilimitado e de fácil acesso, mesmo havendo elevada demanda, seu preço será zero. Porém, o aumento artificial do preço de um bem, por meio de uma legislação que cria uma escassez artificial, ainda não está justificada.

Aqui é onde os efeitos esperados - uma análise de prognose, que se pauta na previsão de fatos que podem acontecer no mundo real - se encontram com a justificativa política - o porquê de determinados efeitos/consequências devam ser alcançados. As patentes protegem ideias inovadoras que se transformam em produtos comercializáveis. Pressupõe-se que é de interesse de todos estimular a criação de novas ideias desse tipo. Mas há um receio de que, caso não haja uma proteção legal contra a cópia dessas ideias - uma inefetividade da escassez artificial criada pelo Direito na forma de uma patente - não existam incentivos para que se criem mais ideias desse tipo (LANDES; POSNER, 2003).

Por outro lado, quando da análise de um dado sistema patentário sob a ótica estrita do Direito Privado, em especial do Direito Empresarial, há que se qualificar tal sistema como um mecanismo de divulgação do conhecimento produzido. Assim, o sistema de patentes seria, sob tal ótica, procedimental, já que permitiria a divulgação do processo produtivo ou produto para toda a comunidade científica, gerando-se mais desenvolvimento econômico e social. Em consequência, a exclusividade deferida ao inventor, por uma única vez, nada mais seria do que um

\footnotetext{
4 Sobre a necessidade de um ferramental teórico para a tomada de decisões jurídicas, ver: CAMINHA, Uinie; ROCHA, Afonso de Paula Pinheiro. Direito e Economia, Responsabilidade Civil Contemporânea e Desenvolvimento Econômico. Disponível em: 〈https://www.uni7.edu.br/periodicos/index.php/revistajuridica/article/view/49/39>. Acesso em: 7 novembro, 2018.
} 
ressarcimento ao investimento feito na invenção, permitindo-se, assim, a continuidade dos processos inventivos 5 .

A patente é um privilegio legal. Tal benefício (privilégio) será concedido ao inventor, permitindo-lhe fabricar, utilizar e/ou vender determinado bem ou processo, de forma exclusiva e por tempo determinado (GÓMEZ ABELLEIRA, 1999). Ou seja, é evidente, quando de sua concessão por um favor legal, sua temporalidade.

O tratamento dos direitos de propriedade industrial, no marco do Direito do comércio internacional, oscila entre sua configuração territorial e a globalização das relações comerciais. Essa última circunstância introduziu a necessidade de rentabilidade dos investimentos realizados por atores de P\&D. Essas coordenadas se manifestam em diferentes momentos da regulamentação internacional dos direitos de propriedade industrial (JIMÉNEZ BLANCO, 1998).

Para o Tribunal de Justiça de Luxemburgo (TJUE), tal privilégio é justificável como uma concessão ao inventor de um direito exclusivo de comercialização/licenciamento do bem, permitindo, com o monopólio da exploração, a recompensa por seus esforços criativos (UNIÃO EUROPEIA, 1974). Tem como objetivo específico garantir ao titular de tal direito, de utilizar sua invenção com vistas a fabricação e comercialização de produtos industriais de forma exclusiva, durante prazo determinado ${ }^{6}$.

Contudo, importa salientar que o sistema de patentes não é feito com o objetivo único de gerar exclusividade ao inventor. A exclusividade, ainda que exista, é entendida somente como uma recompensa ao inventor pelo trabalho realizado. O sistema pretende, assim, a partir da justificativa ostensiva geralmente concedida ${ }^{7}$, contribuir para o desenvolvimento tecnológico e científico dos povos, já que os processos de invenção serão arquivados nos órgãos concedentes da patente e divulgados para a comunidade científica mundial.

\subsection{A Teoria do Interesse Público}

A teoria do Interesse Público pressupõe um sistema coletivista de organização econômica - em oposição a um sistema de mercado, que será explicado mais adiante (OGUS, 2004). Nesse tipo de sistema, o Estado assume como sua a tarefa de dirigir ou estimular certos tipos de comportamento que, em teoria, não ocorreriam de outra maneira, mas que seriam necessários para corrigir as deficiências do mercado (OGUS, 2004). A motivação dessa intervenção seria uma demanda da população para a correção de ineficiências ou de distribuição desigual por parte do

5 O monopólio gerado pelo sistema de patentes, em beneficio do inventor, geraria um incremento dos preços dos produtos resultado do processo inventivo, incentivando a criação de novas ideias. Contudo, este monopólio deve ser limitado, controlado pelo próprio Estado, já que legal. Ademais, não pode ser eterno, já que perpetuaria os efeitos danosos à concorrência e ao bem-estar social. Veja-se, de entre muitos: STORDEUR, Eduardo. Análisis económico del Derecho, Abeledo Perrot, Buenos Aires, 2011, p. 186 e ss.

6 Para aprofundar sobre o sistema de patentes no âmbito da UE, em especial o sistema de proteção unificado das mesmas, veja-se, de entre outros: BRUNS, Alexander. Litigation on Intellectual Property in Europe - Basic Structures and Perspectives, em: STURNER, Rolf; KAWANO, Masanori. Cross Border Insolvency, Intellectual Property Litigation, Arbitration and Ordre Public, Mohr Siebeck, Tubingen, 2011, p. 255 e ss.

7 Interessante tema analisado por Andrea Fusaro, no âmbito da UE, no sentido de que, muitas das vezes, a autonomia da vontade gera uma intervenção privada nos contratos com efeitos públicos, já que as partes defenderiam não somente seus interesses na relação jurídica, mas também os interesses e vontade da coletividade, funcionando como uma verdadeira intervenção privada, com efeito público, na economia contratual. FUSARO, Andrea. Autonomia privata ed intervento pubblico: gli interventi privati che svolgono funzioni pubbliche, em: ALPA, Guido; DANOVI, Remo. Diritto Privato Europeo - fonti ed effetti, Giuffrè editore, Milano, 2004, p. 283 e ss. No mesmo sentido, ver: GARCÍACASTRILLÓN, Carmen Otero. Las patentes en el com- ercio internacional. Madrid: Dykinson, 1997. p. 353 e ss. 
mercado (POSNER, 1974). O Direito que implementa o sistema coletivista de organização econômica é chamado de "regulação" - regulation -, na doutrina anglo-saxã (OGUS, 2004), e que, para evitar confusões terminológicas, no Brasil, pode ser chamado de intervenção econômica do Estado.

A teoria do Interesse Público assume que os mercados econômicos são frágeis e desiguais e que a regulação pelo Estado praticamente não tem custos; perante cada intervenção do Estado existiria uma imperfeição do mercado - imperfeição essa que seria uma justificativa suficiente da própria intervenção (POSNER, 1974). Essa teoria assume que, quando os mercados não são capazes de se autorregular - quando há uma falha de mercado - e quando o Direito privado não é capaz de corrigir as falhas de mercado, é necessária a intervenção do Estado na forma de regulação (OGUS, 2004).

Porém, empiricamente, não existe uma correlação entre regulação e situações onde há falhas de mercado - como externalidades negativas ${ }^{8}$ ou tendências monopolísticas - e, ainda, os resultados de vários tipos de regulação não podem ser explicados como tendo aumentado a igualdade, riqueza ou justiça da sociedade (POSNER, 1974). Portanto, os resultados insatisfatórios da implementação da teoria não seriam consequências de uma falha na teoria em si, na capacidade do Estado em condicionar o comportamento de seus súditos para alcançar o bem da sociedade, mas sim, seriam consequências da inaptidão das pessoas e procedimentos que implementam a regulação (POSNER, 1974).

Essa afirmação de que os problemas da teoria são consequências do pessoal e dos procedimentos é questionável. Ela não considera o fato de que muitas legislações tidas como insatisfatórias são frequentemente desejadas por influentes grupos de interesses; que os burocratas que ocupam os cargos públicos não têm, em princípio, uma remuneração menor do que os trabalhadores da iniciativa privada - considerando o valor agregado em capital humano do burocrata, o fato de que ele receberá salários mais elevados na iniciativa privada como resultado de sua experiência acumulada - o que seria um parâmetro da eficiência do funcionário; e que aqueles que estão dentro de uma agência reguladora também têm incentivos para realizarem bem seu trabalho, se destacar e obter os subsequentes benefícios (POSNER, 1974).

Apesar das críticas à teoria do Interesse Público, não se pode descartar completamente sua validade, pois as outras teorias apresentadas não são capazes de explicar completamente o fenômeno da regulação.

\subsection{A Teoria da Escolha Pública}

A Teoria da Escolha Pública, em vez de assumir que o Estado terá suas atitudes pautadas no bem-estar geral da população e que fará o que puder para alcançar as preferências agregadas da população, assume que as pessoas buscam alcançar seus objetivos pessoais e o fazem de maneira racional (POSNER, 1974).

A teoria assume que o comportamento na arena política não é diferente daquele que ocorre no mercado, pois em ambos os casos os indivíduos agem para maximizar sua utilidade

8 As externalidades são consequências de atividades que se propagam afetando pessoas que não são parte da atividade. Quando tais consequências são custos, se denominam externalidades negativas. Quando são benefícios, se denominam externalidades positivas. Veja-se: SCHMIDTZ, David. El derecho de la propriedad, em: SPECTOR, Horacio. Elementos de análisis económico del derecho, Rubinzal - Culzoni Editores, Buenos Aires, 2004, p. 27 e ss. 
(OGUS, 2004) ${ }^{9}$. Ela não é um método, ou conjunto de ferramentas, mas uma perspectiva que surge da extrapolação dos métodos da economia aplicada à tomada de decisão do comportamento não-mercadológico (MCAUSLAN, 1988). Parte-se do pressuposto de que a livre escolha, o paradigma da troca, se aplica à política e ao processo político - retirando do escopo de sua análise aqueles comportamentos coercivos, não voluntários (MCAUSLAN, 1988).

Isso implica que, a partir do momento que se valora positivamente a troca livre e, negativamente, a troca onde há coerção, a estrutura da tomada de decisões políticas - onde se joga o jogo político - deve ser alterada para beneficiar a escolha livre; a teoria não propõe que se escolham agentes "moralmente superiores que usarão seus poderes" para alcançar o "interesse público" (MCAUSLAN, 1988).

A teoria da Escolha Pública realmente se completa quando se combina o paradigma da troca com uma percepção do agente político como homo economicus - onde os indivíduos que são representados em modelos formais buscam alcançar seu interesse próprio, aumentando sua riqueza. Agindo dessa maneira, não intencionalmente, podem aumentar o bem-estar social, caso o arcabouço legal e institucional propicie isso (MCAUSLAN, 1988).

Mas, de forma simétrica ao que ocorre no mercado, o jogo político também possui falhas político-governamentais, que devem ser evitadas e/ou corrigidas; como a possibilidade de certos partidos políticos tentarem impedir a alternância de poder, excluindo o voto ou uma extensão indevida de seus poderes (MCAUSLAN, 1988).

Por outro lado, é importante lembrar a diferença entre a tentativa descritiva da teoria da Escolha Pública e as consequências normativas de se aderir a ela. O primeiro passo seria o de se aceitar, ou não, que a teoria descreveria a realidade de forma útil. O segundo passo seria o de se basear em atitudes futuras nos postulados desta teoria. Este passo tem consequências normativas.

O objetivo buscado neste capítulo é testar se a teoria da Escolha Pública, ou do Interesse Público, explicariam, de forma satisfatória, a existência de legislações que implementam um sistema de patentes de fármacos.

\section{A ESCOLHA DE UM DISCURSO E A JUSTIFICATIVA PARCIAL}

Como visto até aqui, não se pode assumir que a regulação, por si só, deriva do interesse das autoridades em buscar o interesse público. Nem mesmo é claro o que é interesse público. Por outro lado, os diversos atores, cada um buscando o interesse próprio, são responsáveis pela regulação. São responsáveis por leis e atos normativos que buscam alterar o comportamento dos indivíduos, para que se alcance um fim específico ${ }^{10}$.

Outra coisa completamente diferente é encontrar a melhor forma de fazer isso. Quem elabora e implementa a regulação, e porque o faz, são questões diferentes de como o fazem. E isso abre duas portas interpretativas, sendo a segunda dependente da primeira: i) determinada regulação, apesar de sua justificativa ostensiva, alcança os resultados propostos? ii) determinada

9 Para um exemplo de política pública descrita a partir da Teoria da Escolha Pública, ver: SILVA, Vera Lucia da. A influência da tecnocracia industrial-empresarial na identificação entre desenvolvimento econômico e industrialização na Política de Planejamento Nacional. Disponível em: < https://www.uni7.edu.br/periodicos/index.php/ revistajuridica/article/view/34/24>. Acesso em: 24 de novembro de 2018.

${ }^{10}$ Interessante a análise, neste momento, da teoria de Carl Schmit, para quem, na intenção do Estado de justificar as distintas formas de progresso (desenvolvimento), acaba por justificar, pela atuação de grupos, de um novo progresso, o político. Veja-se, neste sentido: SCHIMITT, Carl. La revolución legal mundial, Hydra Editorial, Buenos Aires, 2005 , p. 61 e ss. 
regulação, em vista de seus resultados, é coerente com o modelo que a justificou - interesse público ou escolha pública? Ou seja, caso a regulação se proponha como implementadora do interesse público, e analisando seus resultados, pode-se dizer que de fato implementa o interesse público e não o interesse de agentes individuais que buscam maximizar seu bem-estar ${ }^{11}$ ?

\subsection{Análise de Impacto Regulatório}

Definir um objetivo político é um ato que independe da definição da forma de sua realização. Podem existir várias formas de se alcançar um mesmo objetivo e elas podem diferir enormemente em eficiência e efetividade.

A Organização para a Cooperação e Desenvolvimento Econômico - OCDE - publicou, em 2008, um manual sobre a importância e a forma de realização de Análises de Impacto Regulatório - AIR (OCDE, 2008). A AIR é um “um processo de identificação e avaliação sistemáticas dos efeitos esperados de propostas regulatórias usando um método analítico consistente, como a análise de custo/benefício" (OCDE, 2008). Uma vez escolhidos os objetivos, é preciso identificar quais são as intervenções capazes de alcançar esses objetivos para que elas possam ser comparadas entre si, no que se refere a eficiência e efetividade (OCDE, 2008). Não basta uma análise da expectativa de ganho de uma intervenção do Estado contra uma situação de não-intervenção. A importância da AIR vem da comparação do desempenho de diferentes formas de se alcançar um mesmo objetivo. Não é porque uma determinada intervenção ajuda a resolver determinado problema que ela é a melhor forma de se fazer isso. A comparação é necessária para se escolher a melhor forma de intervir - ou não - e resolver o problema, assim como delimitar quais serão as pessoas realmente afetadas (OCDE, 2008).

A conclusão de uma análise prévia do problema, levando em consideração os custos das intervenções necessárias para se chegar ao fim esperado, pode ser a não-intervenção ${ }^{12}$. A intervenção deve vir somente quando há uma expectativa de maximização do bem-estar social; a maximização deve levar em conta toda a sociedade, e não somente os grupos de interesse que se mobilizaram em favor ou contra à intervenção ${ }^{13}$.

\footnotetext{
11 Até mesmo no campo jurisdicional poder-se-ia dizer de uma eventual influência da política para as decisões dos magistrados, que poderiam ser influenciados por distintos atores ou ambiente institucional. Para um aprofundamento sobre a matéria, veja-se: DWORKIN, Ronald. Una cuestión de princípios, Siglo XXI Editores, Buenos Aires, 2012, p. 25 e ss. Por seu turno, para Carl Schimitt também já haveria uma Ciência Jurídica Normativa e uma Ciência Social explicativa, que influenciariam o juiz quando da tomada de sua decisão, ainda que afirmara o autor que correta seria a decisão fundamentada na lei posta. Veja-se: SCHIMITT, Carl. Posiciones ante el derecho, Tecnos, Madrid, 2015, p. 16 e ss. A sua vez, Alexy entende que o Direito tem uma dupla natureza. Assim, teria tanto uma dimensão real ou fática, como uma dimensão ideal ou crítica. Os elementos fáticos estarão refletidos na lei e na eficácia social; já a dimensão ideal estará consubstanciada na moral. Quem entende o Direito somente como elemento fático, defenderá o positivismo. Por outro lado, aqueles que entendem o Direito também como elemento moral, o qualificará como elemento para além do positivismo. Veja-se, neste sentido: ALEXY, Robert. La doble naturaliza del derecho, Editorial Trotta, Madrid, 2016, p. 25 e ss.

${ }^{12}$ Há que se falar, ainda, que os recursos do Estado serão sempre escassos. Assim, mesma que exista a intenção na intervenção sempre será feita análise do custo de efetividade do direito derivado da intervenção, e se o custo for maior que o beneficio, ou se ocorrer a ausência do recurso por parte do Estado, então ocorreria a não intervenção. No sentido do custo da intervenção e da escassez de recursos disponíveis em favor do Estado, veja-se: HOLMES, Stephen; SUNSTEIN, Cass R. El costo de los derechos, Siglo XXI Editores, Buenos Aires, 2011, p. 116 e ss.

${ }^{13}$ Importante verificar que, hoje em dia, o Estado, se entendido como a expressão do poder executivo (Governo), já não detêm mais a exclusividade sobre a intervenção na economia. Assim, hoje haveria uma fragmentação sobre o controle da economia, que deixou de ser exclusiva do poder executivo e passou primeiro ao legislativo, depois ao judiciário para, finalmente, chegar aos grupos de interesses organizados da sociedade civil. Veja-se, neste sentido: CASSESE, Sabino. La crisis del Estado, LexisNexis Abeledo-Perrot, Buenos Aires, 2003, p. 67 e ss.
} 
É importante notar que essa é uma afirmação valorativa. O relatório da OCDE pressupõe que a intervenção deve ser justificada com a melhoria do bem-estar social. O que difere sobremaneira da teoria da Escolha Pública. Essa teoria tenta explicar como o Estado de fato intervém na economia. Não é um juízo de valor de como o Estado deveria intervir. O objetivo da contraposição entre o tipo dessas proposições - proposições que tratam sobre fatos e proposições que tratam sobre juízos de valor - é permitir uma crítica politizada, mas empiricamente embasada, às formas de intervenção do Estado, e não às escolhas políticas que colocam determinadas questões como problemas a serem resolvidos.

\subsection{Justificativas para a implementação de regulação}

Existem pelo menos três boas razões que justificam a implementação de regulação: i) falhas de mercado; ii) objetivos sociais, como a equidade; iii) falhas de regulação (OCDE, 2008).

Para tratar do problema do presente artigo, somente será interessante aprofundar na primeira dessas razões. As falhas de mercado são situações em que o mercado, por si só, não consegue alocar os recursos com eficiência, como acontece quando existem externalidades - "o impacto das ações de uma pessoa sobre o bem-estar das outras que não tomam parte da ação" (MANKIW, 2014).

A consequência disso é que o produtor e o consumidor não consideram esses custos na hora de produzir ou consumir um bem (OCDE, 2008). As pessoas afetadas por externalidades negativas não participam da transação, mas mesmo assim arcam com custos que deveriam ter sido confinados à transação. Caso as externalidades criassem um benefício aos terceiros em vez de custos, não seria necessária a intervenção do Estado - este poderia até mesmo estimular os comportamentos que têm como consequência externalidades positivas, como é o caso da educação, saúde, etc.

Porém, quando as externalidades são negativas - se configura uma incapacidade do mercado em absorver esses custos - o Estado pode intervir para tentar solucioná-las.

\subsection{Falha de Mercado do Conhecimento}

Como o conhecimento - que é gênero daqueles bens jurídicos que podem ser patenteados, sendo uma das espécies as ideias inovadoras de aplicação industrial que tiveram atividade inventiva $^{14}$ - tem natureza econômica de bem público ${ }^{15}$, a empresa inovadora não consegue reaver todos seus investimentos em Pesquisa e Desenvolvimento (P\&D) o que geraria uma falha de mercado que poderia fazer com que as empresas investissem em um nível abaixo do socialmente ótimo (PRUD’HOMME, 2016).

Ou seja, o empresário racional, segundo essa explicação, tenderá a investir menos de seu dinheiro em P\&D buscando obter uma inovação comercializável, pois não lhe serão garantidos

\footnotetext{
${ }^{14}$ Para uma análise da tecnologia incorporada ao conhecimento, veja-se, de entre muitos: FERRAZ, Daniel Amin. Da qualificação jurídica das distintas formas de prestação tecnológica: breve análise do marco regulatório internacional. Revista de Direito Internacional, Brasília, v. 12, n. 2, 2015 p. 448-462.

$15 \mathrm{O}$ bem público não é nem rival nem exclusivo. Não ser rival significa dizer que o uso de um bem por uma pessoa não reduz a possibilidade de outra usá-lo. Ser não-exclusivo significa que as pessoas não podem ser impedidas de usá-los. MANKIW, N. Gregory. Princípios de Microeconomia. 6.ed. São Paulo: Cenage Learning, 2014, p. 204.
} 
os frutos da comercialização dessa inovação. Os concorrentes, que também são racionais, simplesmente copiariam a inovação sem arcar com os custos de pesquisa e desenvolvimento, que geralmente são extremamente elevados.

Com o fim exclusivo de estimular a inovação, a maioria dos países criou direitos de exclusão sobre determinados tipos de bens imateriais. A intenção é simular a escassez desses bens que naturalmente não são escassos para que o inventor obtenha um retorno financeiro capaz de estimular inovações futuras. A propriedade funciona, então, não como um fim por si só, mas como meio de se alcançar determinado objetivo (ARAÚJO, 2008, p. 201).

\begin{abstract}
Por outro lado, não podemos perder de vista a dimensão política dos problemas da propriedade intelectual [...]. Se levarmos em conta essa dimensão política e ponderarmos os objectivos tradicionalmente assinalados às principais formas de proteção da propriedade intelectual, concluiremos sem dificuldade que se trata de um regime que deve muito mais a ideia de subsídio público do que à ideia de poder exclusivo in rem: com efeito, trata-se claramente de um expediente para lidar com um tipo peculiar de bens públicos, procurando evitar que as respectivas características estruturais destruam as possibilidades da sua produção espontânea a níveis socialmente eficientes - e esse expediente consiste basicamente na atribuição de monopólios temporários, susceptíveis de gerarem 'quase-rendas' que se tenham por remuneradoras da inovação e do investimento, ainda que se saiba, numa ponderação global, que isso é alcançado à custa da livre circulação de recursos e da livre concorrência por esses recursos. (grifo nosso)
\end{abstract}

Ou seja, a justificativa para a existência da propriedade intelectual, tradicionalmente, tanto na literatura econômica como na jurídica clássica (HETTINGER, 1989), poderia ser explicada pela Teoria do Interesse Público: uma falha de mercado pede que o Estado preserve o interesse de seus súditos por meio de uma intervenção na economia. O interesse público clamaria para que o Estado resolvesse aquilo que a sociedade civil não conseguiria, por si só, solucionar. A próxima parte do presente artigo mostrará como essa última afirmação é contra fática.

\title{
3. REALIDADE ECONÔMICA EMPÍRICA DAS PATENTES DE FÁRMACOS
}

Do até aqui analisado, seria razoável acreditar que a teoria do Interesse Público explicaria os motivos das regulações que implementam sistemas patentários. Ou seja, a proprietização de um bem imaterial - que é uma troca entre acesso e inovação - seria uma resposta regulatória à falha de mercado que ocorre como consequência da natureza de bem público do conhecimento. O Estado, sabendo o que é melhor para a sociedade, resolve esse problema, dando direitos de exploração exclusivos sobre bens que não são rivais.

O problema desse argumento é que uma prova empírica, constatando que as patentes não fazem aquilo que elas deveriam fazer - ou não são a melhor forma de se chegar a esse fim -, muda a teoria que melhor explica a regulação, que melhor explica o sistema de patentes. Ou seja, patentes não existiriam para resolver uma falha de mercado. Não existiriam para beneficiar os súditos e aumentar o bem-estar geral da população. Elas seriam consequência dos interesses pessoais de determinados grupos. E é isto o que a segunda parte do presente artigo tenta mostrar.

\subsection{Os efeitos duplos da regulação das patentes}

A patente funciona como um muro, uma cerca jurídica de uma ideia. Cria fronteiras que delimitam a abrangência dos poderes de exclusão de seu detentor. Continuando a metáfora, pode- 
se dizer que a proteção da patente é ser exercida verticalmente. Tudo que se encontra dentro dos limites da patente pode ser reivindicado por seu detentor. Porém, a patente de um titular não protege o que foi murado ou cercado pelo vizinho. Ela não toca o "terreno do lado" - uma patente válida não afeta outra patente válida, em teoria. Outra patente significa outra ideia inovadora, que passou pelo respectivo processo legal.

Essa metáfora é útil para entender os dois tipos de concorrência que uma patente sofre. Ela compete verticalmente, no que se chama de competição intra-patente - within-patent competition - e compete horizontalmente, no que se chama de competição entre-patentes - betweenpatent competition (LICHTENBERG; PHILIPSON, 2002).

\subsubsection{Competição intra-patentes}

A abordagem analítica tradicional avalia a propriedade intelectual como forma de correção da falha de mercado. Ela avalia os efeitos regulatórios das patentes usando como variáveis o comportamento dos imitadores em potencial da patente, os imitadores do mesmo produto patenteado. $\mathrm{O}$ foco desse tipo de análise é a patente como forma de redução da imitação do produto patenteado (LICHTENBERG; PHILIPSON, 2002). Esse tipo de competição, na indústria farmacêutica, é medido comparando-se o medicamento de referência - que primeiro obteve a patente e arcou com os custos fixos ${ }^{16}$ - e o medicamento genérico (LICHTENBERG; PHILIPSON, 2002) - que é uma cópia do medicamento de referência e não precisa arcar com a maioria dos custos fixos incorridos pelo medicamento inovador, de referência.

Dentre as opções de regulação possíveis para estimular P\&D, a patente é só uma delas um tipo específico de intervenção que pretende alcançar um determinado fim. Para alcançar esse estímulo, poder-se-ia: i) reduzir o custo privado marginal de $\mathrm{P} \& \mathrm{D}$, como é o caso dos incentivos fiscais; ii) aumentar a probabilidade marginal de sucesso da pesquisa, como é o caso de pesquisas públicas que complementam a pesquisa privada; iii) aumentar o lucro ex post da inovação, como é o caso da propriedade intelectual, que cria barreiras intra-patentes à competição - aumentando o tempo ou abrangência da patente (LICHTENBERG; PHILIPSON, 2002). Essas três formas de regulação aumentam os gastos com $\mathrm{P} \& \mathrm{D}$.

Por todo o dito é que o sistema patentário, gerando propriedade sobre bens imateriais, não pode ser análogo à propriedade de bens materiais. É por isso que a patente tem que ser explicada e justificada. Como já foi dito, a patente não é uma forma de se lidar com a escassez natural dos bens. É uma escolha política, dentre outras, para estimular a P\&D e tentar corrigir uma falha de mercado. E, numa sociedade contemporânea, é difícil imaginar a utilidade desse tipo de regulação, caso ela não seja corroborada por evidências empíricas.

\subsubsection{Competição entre patentes}

A competição vertical, dentro de um sistema patentário, é só uma forma de destruição do investimento em P\&D. A outra forma de destruição do retorno do investimento em P\&D é a competição entre patentes. É o resultado da criação de um novo produto, patenteado, que é melhor do que o anterior (LICHTENBERG; PHILIPSON, 2002).

\footnotetext{
${ }^{16}$ São os custos que não variam com a produção; mesmo que o empresário, por exemplo, não produza nada, deve arcar com eles (MANKIW, 2014). No caso do desenvolvimento de medicamentos, esses custos podem ser vários. A própria pesquisa e desenvolvimento, os testes laboratoriais, o registro no órgão regulador, etc.
} 
A competição intra-patentes no caso dos medicamentos se dá basicamente com os medicamentos genéricos, enquanto a competição entre patentes acontece entre os medicamentos de referência; as empresas criam diferentes medicamentos para tratar da mesma doença, o que é chamado de competição terapêutica (LICHTENBERG; PHILIPSON, 2002).

Em ramos de tecnologia de ponta, a competição entre patentes é especialmente importante, pois a demanda por uma determinada invenção pode gerar, como consequência, a criação de um produto melhor, independentemente da validade da patente do produto pioneiro; isso é extremamente importante para as indústrias de biotecnologia e farmacêutica (LICHTENBERG; PHILIPSON, 2002).

Os fármacos não são criados como um bem por si só. Os medicamentos têm como objetivo tratar determinadas doenças, condições. Eles têm um fim terapêutico específico - obviamente podendo ser aplicado para tratar mais de uma doença. Quando uma patente de fármaco é registrada, ela protege o medicamento em si de competir com cópias dele mesmo. Protege o princípio ativo, forma de dispersão, etc. A proteção é dada para o medicamento, não para sua aplicação. Se um medicamento tem como objetivo tratar o câncer de pele, nada impede que o concorrente invente uma nova droga que trate esse câncer de forma mais eficaz, com menos efeitos colaterais, ou a um menor custo, por exemplo. Nesses casos, a patente não tem utilidade para garantir os retornos dos investimentos em P\&D.

Isso significa que, mesmo antes do término do prazo da patente, o medicamento sofre competição através da criação destrutiva (LICHTENBERG; PHILIPSON, 2002). A criação e consumo de novos produtos, métodos de produção ou transporte, novos mercados, novas formas de organização industrial, são os elementos fundamentais do capitalismo; novas criações revolucionam seus mercados num "processo de mutação industrial [...], que incessantemente revoluciona a estrutura econômica pelo lado de dentro, incessantemente destruindo o [processo industrial] antigo, incessantemente criando um novo. Esse processo de criação destrutiva é o fato essencial sobre o capitalismo" (SCHUMPETER, 2003, p. 83).

Qualquer regulação que pretenda estimular os investimentos em P\&D se utilizando de patentes deve levar em consideração não só a competição vertical - intra-patente - como também a competição horizontal - entre patentes, caso ela pretenda se justificar como uma manifestação do interesse público. Uma determinada intervenção do Estado pode se mostrar muito efetiva em reduzir a cópia de um medicamento e, ao mesmo tempo, altamente inefetiva no que concerne à competição entre patentes (LICHTENBERG; PHILIPSON, 2002).

Caso a regulação não leve em conta os dois tipos de competição, é possível que o estímulo ao investimento não seja compensado. Uma exclusividade mais duradoura - aumento da proteção da concorrência intra-patentes - será mais interessante para que outras pessoas invistam para competir com o mesmo produto, mas sob a proteção de outra patente - a competição terapêutica entre patentes, no caso dos fármacos (LICHTENBERG; PHILIPSON, 2002). Com a criação e registro de um novo medicamento com a mesma aplicação terapêutica que seja melhor do que o anterior - uma criação destrutiva - os ganhos exclusivos garantidos pela patente do primeiro empresário serão corroídos, assim como a sua expectativa de retorno dos investimentos em P\& D (LICHTENBERG; PHILIPSON, 2002).

\subsection{Resultados empíricos}

A indústria farmacêutica, por ser extremamente regulada e uma das maiores investidoras em inovação, proporciona um solo fértil para a pesquisa empírica sobre os efeitos das patentes 
como estímulos para a P\&D. O presente estudo se baseou em uma extensa pesquisa que avaliou os efeitos teóricos e empíricos das competições intra e entre patentes no investimento das empresas de fármacos em P\&D. Não seria interessante aqui, por uma limitação de tema e espaço, reproduzir os caminhos metodológicos dessa pesquisa, mas apenas utilizar suas conclusões ${ }^{17}$.

O estudo de Frank Lichtenberg e Tomas Philipson (2002) mostrou que, no mínimo, a competição terapêutica entre patentes é tão relevante quanto a competição intra-patentes. Novos medicamentos corroem a expectativa de retorno com a inovação tanto quanto a entrada de medicamentos genéricos, porém, a competição entre patentes ocorre antes mesmo da queda da patente, o que não ocorre na competição intra-patentes (LICHTENBERG; PHILIPSON, 2002). Isso significa que a patente, mesmo sem concorrência desleal, não funciona da forma que deveria funcionar para ser coerente com sua justificativa ostensiva - para ser algo mais que um simulacro de direito de propriedade e realmente estimular a inovação.

Essas afirmações são corroboradas em outros estudos, que minimizam a relevância da escassez juridicamente imposta, frente a possibilidade de acesso a conhecimento útil.

\subsection{Da falta de evidência da necessidade de um sistema patentário}

Uma patente não é a única forma de tentar proteger os investimentos incorridos na criação de ideias. Partindo dessa premissa, a sua utilização deve ser justificada em um contexto de implementação de uma política pública. Devem existir fatos que corroborem com a hipótese de que, dentro do pool de formas jurídicas disponíveis pelo legislador, a patente é a melhor delas.

Foi exatamente isso que a National Research Council (2004) não conseguiu fazer. O estudo pretendia avaliar se o crescimento da competitividade da indústria americana dos anos 1980 continuou nos anos 1990. O estudo conclui (NATIONAL RESEARCH COUNCIL, 2004) que os anos 90 foram uma década ainda mais dinâmica, mas não consegue correlacionar esse dinamismo à utilização do sistema patentário.

Mesmo as patentes sendo extremamente utilizadas nessa década, não havia estudos suficientes para corroborar uma forte correlação - ou mesmo causalidade - entre a utilização desse sistema e o dinamismo da indústria americana. Os fatores descritos como sendo os responsáveis por esse crescimento foram consequência de uma série de estratégias de negócios da iniciativa privada, como a especialização da produção, redução de custos, melhorias nos processos de produção, assim como uma série de políticas macro e microeconômicas, como a redução do déficit público, políticas monetárias conservadoras, políticas de financiamento e uma flexibilização das políticas antitruste (NATIONAL RESEARCH COUNCIL, 2004). Outras formas privadas de controle do comportamento podem ser responsáveis pelo dinamismo dos anos 90 . A utilização de contratos para a proteção de segredos industriais, proibição de engenharia reversa e não-competição também estava incluída nesse contexto de fertilidade econômica (NATIONAL RESEARCH COUNCIL, 2004).

A conclusão de que a propriedade intelectual, por si só, não poderia receber o crédito por ter participado nesse novo boom econômico é consequência direta da inexistência de estudos que avaliaram essa correlação. Mas, mesmo assim, o sistema patentário americano continuou dinâmico de um ponto de vista legislativo, sendo objeto de várias reformas estruturais (NATIONAL

${ }^{17}$ Caso o leitor tenha interesse sobre como a pesquisa foi feita, poderá consulta-la em: LICHTENBERG, Frank R; PHILIPSON, Tomas J. The Dual Effects of Intellectual Property Regulations: Within- and Between-Patent Competition in The US Pharmaceuticals Industry. Disponível em: 〈https://www.chicagobooth.edu/assests/stigler/178.pdf〉. Acesso em: 24 de novembro de 2016.

R. Jur. FA7, Fortaleza, v. 16, n. 1, p. 61-78, jan./jun. 2019 
RESEARCH COUNCIL, 2004). Não só isso, o número de patentes registradas e o número de execuções (enforcements) de patentes contra infringentes só tem aumentado (NATIONAL RESEARCH COUNCIL, 2004).

Ou seja, as políticas públicas patentárias eram feitas no escuro, num vácuo de informação e referência para com a realidade dos fatos. Contudo, mesmo assim, o sistema patentário recebia forte atenção legislativa.

Isso nos leva a corroborar a hipótese de que não é o interesse público a teoria que melhor explica a existência de um sistema de patentes. Mas, sim, a escolha pública, que sofre influências e pressões determinadas.

\section{4. $O$ argumento contra as patentes}

Não só aparentemente existe uma tendência a justificar o sistema patentário sem evidências que suportem a sua superioridade em relação ao seu custo de oportunidade, como existem evidências de que os direitos exclusivos gerados pelas patentes podem criar muitos problemas por si só.

Se esse for o caso, o sistema patentário não é consistente com a justificativa ostensiva de que ele existe para solucionar falhas de mercado que, sem a intervenção do Estado, não seriam solucionadas.

A evidência empírica sugere que as indústrias só buscam proteção legal para as inovações uma vez que elas exaurem seu potencial de crescimento, não no momento mais inovador, de crescimento rápido das inovações que geram novas indústrias (BOLDRIN; LEVINE, 2012).

Não só isso, a evidência também aponta que um sistema de patentes fraco pode aumentar marginalmente o ritmo da inovação, com efeitos colaterais limitados, enquanto um sistema de patentes forte pode retardar a inovação com muitos efeitos colaterais (BOLDRIN; LEVINE, 2012).

De forma contra intuitiva à Teoria do Interesse Público, mas de maneira completamente coerente com a Teoria da Escolha Pública, existe uma tendência à evolução da legislação para uma maior rigidez e proteção do sistema de patentes na medida em que as indústrias envelhecem e estagnam - sendo que essa demanda por leis mais rígidas não surge das firmas jovens e inovadoras (BOLDRIN; LEVINE, 2012).

Na experiência americana, nos 60 anos de existência de um sistema patentário forte e dinâmico, a expectativa, pressupondo uma justificação político-jurídica a partir da Teoria do Interesse Público, seria um robusto corpo de evidências corroborando a eficácia de um sistema patentário, levando em conta, inclusive, o custo de oportunidade. Contudo, não é isso o que se observa.

No cenário americano desses últimos 60 anos, teria havido um aumento no número de patentes concedidas, mas sem o correspondente aumento em produtividade ou inovações úteis (BOLDRIN; LEVINE, 2012). O mesmo aumento no número de patentes também não corresponde a um aumento no investimento em $\mathrm{P} \& \mathrm{D}$, ao mesmo tempo que houve um grande aumento no gasto legal discutindo a validade das patentes ou sua infração, sendo que a maior parte das patentes existentes não está em uso e são usadas por empresas que estão "morrendo", para processar outras empresas que de fato estão inovando (BOLDRIN; LEVINE, 2012). 


\section{CONCLUSÃo}

Como visto acima, não faz sentido justificar a exclusão do acesso a um bem imaterial, afirmando que o objetivo dessa medida seria o bem da coletividade, se não se comparam as opções, como sugere a OCDE, por meio de uma Análise de Impacto Regulatório. Tomando como correto o resultado dos estudos apresentados, a regulação de bens imateriais, com o intuito de estimular a inovação, não pode ser feita sem a comparação das opções de políticas públicas rivais, que têm o potencial de alcançar o mesmo objetivo pretendido.

Uma vez delimitado qual o problema a ser resolvido - o sub investimento em P\&D, para gerar inovação -, e o que a patente é - uma tentativa jurídica de criar a escassez artificial de um bem naturalmente não escasso -, é preciso identificar e comparar as outras formas de se alcançar a resolução do problema para escolher a melhor entre elas - que talvez possa ser: não fazer nada. Esse processo é o que justificará a escolha regulatória, uma escolha essencialmente política.

Porém, se a escolha for incoerente com esse processo, não se pode dizer, com certeza, que sua intenção foi elevar o bem-estar social. A premissa necessária para se chegar a essa conclusão - e de difícil refutação - é que a comparação entre diferentes formas de regulação é a melhor forma de avaliar qual será a mais bem-sucedida para resolver o problema. E a que melhor resolver o problema será, pelo menos em teoria, a que mais elevará o bem-estar social.

Se a regulação foi escolhida sem esse processo, ela não pode ser justificada como a que mais elevará o bem-estar social. Se o regulador, tendo os meios disponíveis, não consegue provar que a sua política pública elevará o bem-estar social, a Teoria do Interesse Público não é capaz de explicar o surgimento e manutenção dessa política - que, no caso, seria o sistema de patentes. O sistema de patentes não existiria para corrigir uma falha de mercado, visando o interesse da coletividade. Ele não pode ser justificado como visando esse fim - pelo menos não de forma coerente. Mas ele pode ser explicado pela Teoria da Escolha Pública. Por interesses de determinados grupos, a legislação existe. A não ser que se admita que a legislação possa surgir de forma espontânea, sem motivações políticas de determinados agentes, a Teoria da Escolha Pública é a que melhor responde à pergunta sobre as origens da existência de um dado sistema de patentes.

Com isso, o intuito deste trabalho é meramente desconstruir o argumento, muito popular na literatura especializada, de que as patentes de fármacos existem para resolver uma falha de mercado. Se isso acontece de fato ou não, a justificativa não pode ser a Teoria do Interesse Público. O que motivaria essa legislação, e é essa a hipótese do presente estudo, são interesses de grupos específicos que pretendem obter benefícios - mas sem que essa afirmação conote algum tipo de ilegalidade ou imoralidade. Essa parece ser a melhor explicação teórica, por uma simples questão de coerência interna entre elas e os fatos.

Caso a regulação das patentes passe a ser sensível às formas de justificação exigidas pela OCDE, por exemplo, o resultado do presente estudo poderá ser alterado.

\section{REFERÊNCIAS}

ALEXY, Robert. La doble naturaleza del derecho, Editorial Trotta, Madrid, 2016.

ARAÚJO, Fernando. A Tragédia dos Baldios e dos Anti-Baldios: O problema do Nível Óptimo de Apropriação. Coimbra: Almedina, 2008.

BOLDRIN, Michele; LEVINE, David K. The Case Against Patents, 2012. Disponível em: https://files.stlouisfed.org/files/htdocs/wp/2012/2012-035.pdf. Acesso em 10 de nov de 2018. 
BRASIL. Constituição (1988). Constituição da República Federativa do Brasil de 1988.

BRUNS, Alexander. Litigation on Intellectual Property in Europe - Basic Structures and Perspectives, em: STURNER, Rolf; KAWANO, Masanori. Cross Border Insolvency, Intellectual Property Litigation, Arbitration and Ordre Public, Mohr Siebeck, Tubingen, 2011.

CAMINHA, Uinie; ROCHA, Afonso de Paula Pinheiro. Direito e Economia, Responsabilidade Civil Contemporânea e Desenvolvimento Econômico. Revista Jurídica da FA7, Fortaleza, v. 12, n. 2, p. 33-47, jul./dez. 2015. Disponível em: https://www.uni7.edu.br/periodicos/index.php/ revistajuridica/article/view/49/39. Acesso em: 7 novembro, 2018.

CASSESE, Sabino. La crisis del Estado, LexisNexis Abeledo-Perrot, Buenos Aires, 2003.

DWORKIN, Ronald. Una cuestión de principios, Siglo XXI Editores, Buenos Aires, 2012.

EUROPEAN UNION. Court of Justice. Merck \& Co. Inc. vs Stephar BV; Petrus Stephanus Exler. Reference for a preliminary ruling: Arrondissementsrechtbank Rotterdam - Nether- lands. - Patents - Pharmaceutical products. Case 187/80. Sentence, ${ }^{14}$ July 1981. Disponível em: http:// eur-lex.europa.eu/legal-content/EN/TXT/HTML/?uri=CELEX:61980CJ0187\&from=FR.

FERRAZ, Daniel Amin. A concentração empresarial no contexto da economia internacional. In: FERRAZ, Daniel Amin (Org.). Direito empresarial: marco jurídico de internacionalização das empresas brasileiras. Curitiba: CRV, 2012.

FERRAZ, Daniel Amin. Da qualificação jurídica das distintas formas de prestação tecnológica: breve análise do marco regulatório internacional. Revista de Direito Internacional, Brasília, v. 12, n. 2, 2015.

FUSARO, Andrea. Autonomia privata ed intervento pubblico: gli interventi privati che svolgono funzioni pubbliche, em: ALPA, Guido; DANOVI, Remo. Diritto Privato Europeo - fonti ed effetti, Giuffrè editore, Milano, 2004.

GARCÍA-CASTRILLÓN, Carmen Otero. Las patentes en el comercio internacional. Madrid: Dykinson, 1997.

GÓMEZ ABELLEIRA, Francisco Javier. Litigios entre empresario y trabajador sobre patentes, secretos industriales y derechos de autor en los Estados Unidos. Santiago de Compostela: Universidade da Coruña, 1999.

HETTINGER, Edwin C. Justifying Intellectual Property, 1989. Disponível em: https:// www.jstor.org/stable/2265190. Acesso em: 24 de novembro de 2016.

HOLMES, Stephen; SUNSTEIN, Cass R. El costo de los derechos, Siglo XXI Editores, Buenos Aires, 2011.

HUME, David: Uma Investigação Sobre os Princípios da Moral. Campinas: Editora Unicamp, 2013.

JIMÉNEZ BLANCO, Pilar. El derecho aplicable a la protección internacional de las patentes. Granada: Comares, 1998.

LANDES, William M.; POSNER, Richard A. The Economic Structure of Intellectual Property Law. Cambridge: Harvard University Press, 2003.

LICHTENBERG, Frank R; PHILIPSON, Tomas J. The Dual Effects of Intellectual Property Regulations: Within- and Between-Patent Competition in The US Pharmaceuticals Industry, 2002. Disponível em: https://www.chicagobooth.edu/assests/stigler/178.pdf. Acesso em: 24 de novembro de 2016. 
MANKIW, N. Gregory. Princípios de Microeconomia. 6.ed. São Paulo: Cenage Learning, 2014.

MAS VERDÚ, Francisco. Competitividad Internacional e Innovación, em: DOMÈNECH i DE SORIA, Josep. Economía Mundial, Tirant lo Blanch, València, 2010.

MCAUSLAN, Patrick. Public Law And Public Choice, 1988. Disponível em: http://onlinelibrary.wiley.com/doi/10.1111/j.1468-2230.1988.tb01781.x/epdf. Acesso em: 14 de novembro de 2016.

NATIONAL RESEARCH COUNCIL. A Patent System for the 21st Century, 2004. The National Academies Press, Washington, DC. Disponível em: https:/www.nap.edu/read/10976/chapter/4\#19. Acesso em 10 de nov de 2018.

OCDE. Introductory Handbook for Undertaking Regulatory Impact Analysis, 2008. Disponível em: https://www.oecd.org/gov/regulatory-policy/44789472.pdf. Acesso em: 14 de novembro de 2016.

OGUS, Anthony. Regulation: Legal Form and Economic Theory. Portland: Hart Publishing, 2004.

PLANT, Arnold: The Economic Theory Concerning Patents of Inventions, 1934. Disponível em: http://emilkirkegaard.dk/en/wp-content/uploads/The-Economic-Theory-Concerning-Patents-for-Inventions.pdf Acesso em: 7 novembro, 2016.

PORTUGAL, André. Decisão judicial e racionalidade: crítica a Ronald Dworkin, Sergio Antonio Fabris Editor, Porto Alegre, 2017.

POSNER, Richard A. Theories of Economic Regulation. 1974. Disponível em: http:// www.thecre.com/oira/wp-content/uploads/2016/03/Posner.pdf. Acesso em: 12 de novembro de 2016.

PRUD'HOMME, Dan. IP-Conditioned Government Incentives in China and the EU: A Comparative Analysis of Strategies and Impacts on Patent Quality in PRUD'HOMME, Dan; SONG, Hefa. Economic Impacts of Intellectual Property-Conditioned Government Incentives, 2016. Disponível em: http://link.springer.com/book/10.1007\%2F978-981-10-1119-1. Acesso em: 23 de novembro de 2016.

SANTOS, António Marques dos. Transferência internacional de tecnologia, economia e direito: alguns problemas gerais. Lisboa: Centro de Estudos Fiscais, 1984. (Cadernos de Ciência e Técnica de Fiscal, 132).

SCHIMITT, Carl. La revolución legal mundial, Hydra Editorial, Buenos Aires, 2005.

SCHIMITT, Carl. Posiciones ante el derecho, Tecnos, Madrid, 2015.

SCHMIDTZ, David. El derecho de la propiedad. In: SPECTOR, Horacio. Elementos de análisis económico del derecho, Rubinzal - Culzoni Editores, Buenos Aires, 2004.

SCHUMPETER, Joseph A. Capitalism, Socialism and Democracy. Londres: Taylor \& Francis, 2003.

SILVA, Vera Lucia da. A influência da tecnocracia industrial-empresarial na identificação entre desenvolvimento econômico e industrialização na Política de Planejamento Nacional. Revista Jurídica da FA7, Fortaleza, v. 12, n. 2, p. 61-85, jul./dez. 2015. Disponível em: https:// www.uni7.edu.br/periodicos/index.php/revistajuridica/article/view/34/24. Acesso em: 24 de novembro de 2018 . 
Patentes e regulação econômica aplicada aos fármacos

STORDEUR, Eduardo. Análisis económico del Derecho, Abeledo Perrot, Buenos Aires, 2011. UNIÃO EUROPEIA. Tribunal de Justiça. Centrafarm BV; Adriaan de Peijper vs. Sterling Drug Inc. Caso 15/74. Setença, 31 de outubro de 1974. Disponível em: http://eur-lex.europa.eu/ legal- content/PT/TXT/PDF/?uri=CELEX:61974CJ0015\&from=FR.

Recebido em: 14 set. 2018.

Aceito em: 29 mar. 2019.

78 R. Jur. FA7, Fortaleza, v. 16, n. 1, p. 61-78, jan./jun. 2019 